\title{
Botswana's Age Structural Transition Has Unleashed the Demographic Dividend (DD) Opportunities: Is the Country up to the Task of Capitalising on the DD?
}

\author{
Neo Nkwe', Elizabeth Poloka Mukamaambo', Brothers W. Malema² \\ ${ }^{1}$ Department of Population Studies, University of Botswana, Gaborone, Botswana \\ ${ }^{2}$ Department of Economics, University of Botswana, Gaborone, Botswana \\ Email: malemabw@mopipi.ub.bw
}

How to cite this paper: Nkwe, N., Mukamaambo, E.P. and Malema, B.W. (2017) Botswana's Age Structural Transition Has Unleashed the Demographic Dividend (DD) Opportunities: Is the Country up to the Task of Capitalising on the DD? Open Access Library Journal, 4: e4189. https://doi.org/10.4236/oalib.1104189

Received: November 23, 2017

Accepted: December 26, 2017

Published: December 29, 2017

Copyright $\odot 2017$ by authors and Open Access Library Inc.

This work is licensed under the Creative Commons Attribution International License (CC BY 4.0).

http://creativecommons.org/licenses/by/4.0/

\begin{abstract}
Through review of available literature and analysis of available data, this paper investigates the nature and process of age structural transition (AST) in Botswana from 1966 to 2016. It provides a comprehensive picture of the age structural transition using the censuses of 1971, 1981, 1991, 2001 and 2011. The theoretical framework used is the Demographic Transition theory and where other appropriate theoretical frameworks have been used to augment it. Botswana has entered a demographic transition where the levels of both fertility and mortality have gone down. Life expectancy that should normally increase during the transition has fluctuated mainly due to the effect of HIV related deaths in the country. As a result, the issue of ageing that is usually associated with the demographic transition does not seem to be a problem for Botswana as the proportion of those aged 65 years and above has remained almost constant over the forty years period under discussion. The harnessing of the dividend may be frustrated by glimpses of perceived increases in corruption and failure to create adequate employment opportunities for the youth, including graduates.
\end{abstract}

\section{Subject Areas \\ Demography, Economics}

\section{Keywords}

Age Structural Transition, Demographic Dividend, Dependency, Economy, Botswana 


\section{Introduction}

Botswana, a landlocked country situated in Southern Africa, became independent in 1966. At the time of independence, the country with a population of less than half a million inhabitants was one of the poorest countries in the world with the per capita income at the time estimated at US $\$ 84$ [1]. Furthermore, the economy was largely dependent on agriculture for livelihood [2]. However, with the discovery of minerals including diamonds in 1967, the economy started growing rather rapidly, changing the lifestyles of the Batswana (Botswana citizens). This transformation resulted from several national development plans (NDPs), programmes and policies leading to an improvement in health, education, employment, water and other basic needs. This is because NDPs in Botswana involve extensive consultation and prioritization of key issues by Government and Local Authorities, wherein the focus of the resultant plan would be on the key issues of concern emanating from the national, as well as local government plans, strategies and policy thrusts [3]

To date, Botswana is considered to have gained considerable development specifically in the following areas: population growth reduction as a result of fertility and mortality reduction, youth and economic empowerment through various youth programmes, and strong commitment to a number of declarations and protocols aimed towards human rights and sexual and reproductive health needs [2].

Although Botswana has made these strides in development, she faces major challenges in some areas such as poverty, inequality, high teenage pregnancy, gender inequality, high prevalence of HIV and AIDS, with the latter having resulted in a decline in the life expectancy that was realised in the early 1990s. Also as a result of high HIV prevalence, more financial resources are being diverted to programmes aimed at mitigating its impact, including the emerging non-communicable diseases (NCDs). Issues related to the quality of education and high unemployment especially among the youth remain critical [2]. All these factors need to be taken care of in order for the country to maximise on the expected demographic dividend provided by its increasing economically active population.

The idea of age structural transition (AST) and the associated outcomes of demographic dividend and window of opportunity demographically have been topical since the turn of the $21^{\text {st }}$ Century. The paper attempts to establish three aspects in relation to the AST; whether there is evidence of AST in Botswana. If there is, whether or not it is following the expected trend as in other countries that have gone through the stage and lastly whether the country has entered into the demographic window of opportunity to harness or maximize the dividend. Benefits and policy implications of the age structural transition are also discussed.

\section{Demographic Transition Theory and the AST}

Several definitions have been used by demographers to define and explain the 
age structural transition (AST). [4] defines it as the process and consequence of a shift in the age structure of a population from young to aged population or a passing of generations or cohorts of differing ages and sizes across key life-cycle stages. For [5] and [6], it is a process where a population undergoes changes in its age structure from a youthful one to an ageing population. [7] and [8] define AST as a shift from young age structure to old age structure. [9] argues that age-structural transitions usually refer to the gradual process of a "young" population moving to an "aged" one because of changes in age structure over time. It therefore means that a decline in fertility rates leads to a reduction in the number of children being born and a change in the proportions of the population in different age groups while mortality changes mean a greater proportional change in certain age groups and sexes since mortality is sex and age selective.

Demographically, the age structural transition is grounded in the demographic transition theory which purports that once a country realises a certain level of socio-economic development, both fertility and mortality levels will change from high rates to lower rates. This then results in fewer children being born and people living longer in such populations mainly due to the reduction in infant mortality. Figure 1 below, adapted from [10] explains how the above changes occur. [10] states that the age-structural transition involves changes produced primarily by declines in fertility during the demographic transition. This process in turn is reported to lead to survivorship changes which then bring about a growth in the number of older aged people in populations because mortality declines especially at younger ages brings about increases in life expectancy in such populations. The reductions in birth cohorts brought about by this process coupled with migration flows thus bring about a change in the age and sex structure of the population. However, [11] states that in a relatively closed population where emigration and immigration are relatively small, age structure is shaped largely by the changes in fertility and mortality. Figure 1 further shows that this process is cyclical or continuous; the social and economic impacts experienced within a country will drive both the demographic processes of a given country as well as change its age structural transition.

Based on the above explanation, the theory also holds that during the change from high birth rates to low birth rates there is a window of opportunity, where

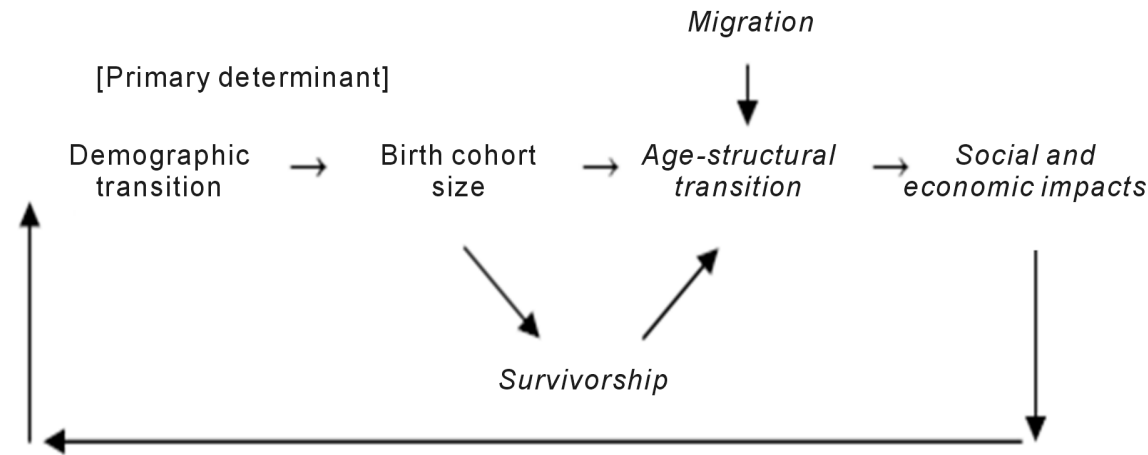

Figure 1. From demographic transition to age-structural transition. Source: [4]. 
those who were many when they were born enter the economically active age group and participate in the production of goods and services. This enables them to create wealth and generate savings for future consumption when they enter old age provided they were able to secure or get employment. Once the window of economic advancement is realised because of the bulge in the working age population, the dependency ratio is reduced meaning that the dependents are smaller than the working population upon whom they depend. This phenomenon reduces the burden of dependence upon the economically active population, creating a window for educational advancement, wealth generation and savings. This observation could be said to be theoretically correct depending on whether the creation of wage employment is enough to accord the working population the opportunity for productive engagement within the modes of commerce. A failure to create opportunities for productive economic engagement in the form of wage employment may render part of the economically active population dependents, implying that the dependency ratio calculated using age groups alone could be underestimated.

\section{Age Structural Transition in Botswana}

To assess changes in a population age structure, two main age presentations are used. These are the population pyramids as constructed during the censuses and the population distribution in broad age groups also known as the economically active age categories. The three age groups used are $0-14$ years old demographically considered to be too young to work; the $65+$ year age group which comprises mainly of those regarded as too old to work and the majority in this group are retired. Both these two groups are referred to as dependents. The 15 - 64 year old group is regarded as the working age group which is ideally responsible to produce all goods and services and it is this group upon which the younger and older age groups depend. This is where the idea of dependency ratio comes from. This is the ratio of those in the dependent age groups to 100 of those in the working age group.

\subsection{The Age Structure}

The age structure of the population is mostly influenced by both mortality and fertility changes in a population. A large proportion of those in the age group 0 - 14 implies that the level of fertility is high, that a high number of children are being born, resulting in a youthful population. This can be reflected in the shape of a pyramid that has a broad base or is bell-shaped in appearance; the base of a related population pyramid should be wider than the rest of the pyramid. The proportion of the population aged 0 - 14 is closer to 40 percent or higher and of those aged 65 and above should not be more than 10 percent and the rest is made up of the population aged 15 - 64. Where there is a shift in the age structure from young to old, the proportion of the young goes down; resulting in a bulge in those aged 15 - 64 years as well as a relative increase in the proportion 
of those aged 65 years and above. While this may pose changes in the long run, there are some advantages in the interim period. The advantages are referred to as demographic dividend which is defined as: an increase in opportunities for economic growth because of a decline in the birth and death rates and window of opportunity when there are more people in the working population as opposed to the dependent population. It is an opportunity because it is conducive for rapid economic development for the country especially if there is low unemployment among those in the working age group. It could be an advantage for a country to have such a population in terms of future work force but a disadvantage at the time being the cost of child care. A sustained low fertility produces an aging population in the long run with proportionally fewer people at the base and more at the middle and at the top. When a population has a large proportion of those 65 years and older, the median age increases, and the population is said to be ageing.

The age structural transition is therefore seen as a long-term process which completely reshapes a population's age structure. Therefore, there is a distinct pattern of change which occurs in a population's age structure over the course of the age structural transition. These shifts can be seen in the way that the different measures of ageing change and in the changing shape of the population pyramid [11]. The two scenarios are discussed below:

Figure 2 and Figure 3 provide population pyramids of the population for Botswana during the past four censuses to assess whether a shift in the age structure has taken place in the country. From the pyramids below, it is clear that changes have been taking place in the age structure of the population of Botswana since the first complete census of 1981. In a nutshell the pyramids as provided show the following: for the period 1981 there is a clear broad base and narrowing from ages 5 upwards, a clear bell-shaped structure; in 1991, there is a clear shift, the base is not as broad as was the case in 1981, but still bell-shaped structure; for 2001 there is an indication of the bulge in the middle age and for 2011; the bulge is moving up.

Secondly, Table 1 shows the population of Botswana in broad age groups and it demonstrates whether the population of Botswana is becoming younger or older. The table shows that the proportion of those aged below 15 years have declined over the years from 47.5 percent of the total population in 1971 to 32.6 percent in 2011. Those aged 65 years and over have remained almost constant at 5 percent. Therefore, the main gain from the reduction in the proportion of the population aged $0-14$ years over the reference period is among the middle age group of 15 - 64 years. The ageing index, another indicator of population ageing, which is defined as the number of persons aged at least 65 years per 100 of those aged less than 15 years is also presented in the table. The index shows a steady increase from 1971 to 2011, implying a shift in the age structure of the population. The index has increased from 11.8 to 16.9 during the reference period. However, given the somewhat constant proportion of those age 65 years and over, it means the shift has not yet reached those aged 

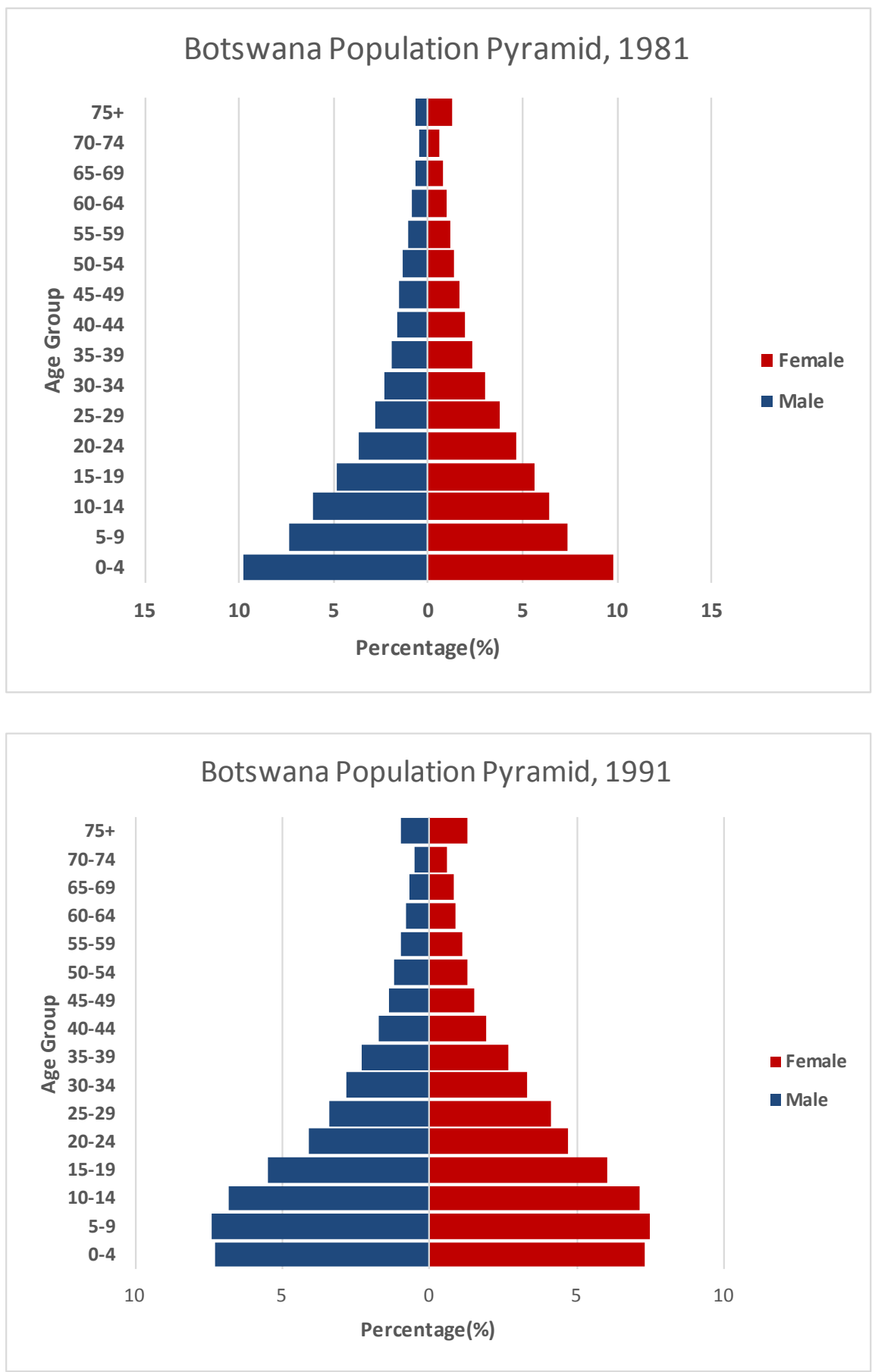

Figure 2. Botswana population pyramids for the years 1981 and 1991. Source: [12].

at least 65 , as it has remained almost constant over the years. Specifically, the proportion of those aged less than 15 years of age has decreased from 47.5 percent in 1971 to 32.6 percent in 2011. This has resulted in the proportionate increase in those aged 15 - 64 years of age, basically at the expense of those aged less than 15 years of age. The low life expectancy is also evident in the near consistent proportion of those in the age group 65 years and over, which has remained almost constant over the years. 

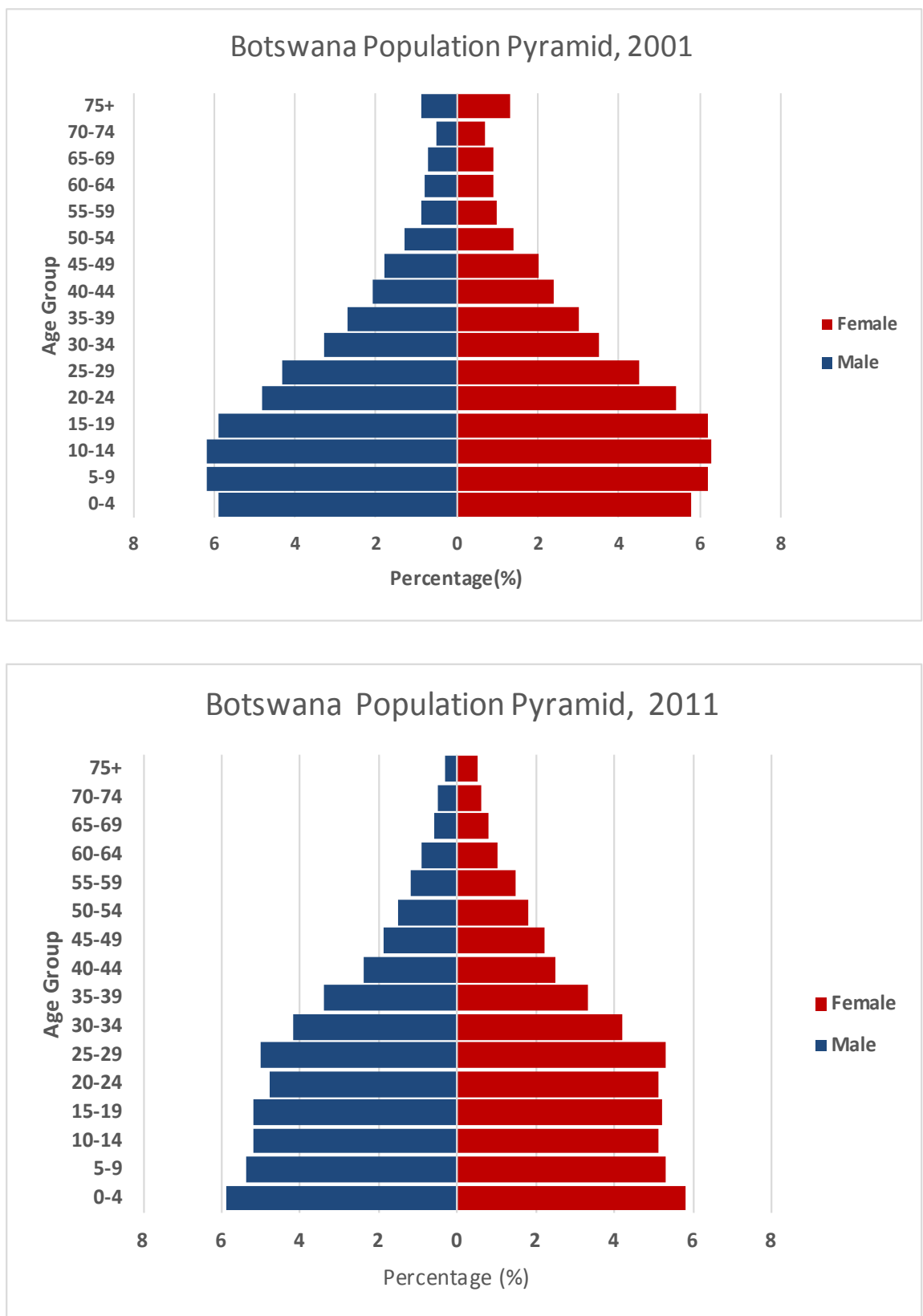

Figure 3. Botswana population pyramids for the years 2001 and 2011. Source: [12].

Table 1. Percent distribution of the population of botswana by broad ages groups.

\begin{tabular}{ccccc}
\hline Estimation Period & $<15$ & $15-64$ & $65+$ & Ageing Index \\
\hline $1971^{\star}$ & 47.5 & 46.9 & 5.6 & 13.0 \\
1981 & 47.6 & 47.6 & 5.1 & 11.8 \\
1991 & 43.2 & 51.5 & 4.9 & 12.5 \\
2001 & 36.6 & 58.2 & 5.0 & 15.0 \\
2011 & 32.6 & 62.4 & 5.0 & 16.9 \\
\hline
\end{tabular}

Source: [13], [14], [15], [16] and [17]. *Incomplete census. 
The age structural transition has also caused changes in the total dependency ratio which comprises children less than 15 years and adults above 64 years, usually referred to as the child dependency ratio and the old age dependency ratio. [18] argues that a declining proportion of children and a simultaneous increase in the share of the youth and working-age adult population lowers dependency ratios and opens a window of opportunity for economic growth as age structures mature and a larger share of the population enters the workforce. During the age structural transition, as fertility and mortality declined, large cohorts born before the fertility decline moved into working ages. As a result, there has been a decline in dependency levels leading to potential economic growth due to the window of opportunity that such a phenomenon presents (See Figure 4).

Looking at Figure 4, there generally has been a reduction across all dependency ratios over the years, with the total dependency ratio declining from 113 dependent persons per 100 working age persons in 1971 to 60.3 dependent persons per 100 working age persons in 2011. [6] states that, declining dependency ratios due to changes in the age structure present the likelihood for a favourable impact on the economy as was observed in Sri Lanka. This might also apply for Botswana as there are more people in the working population as opposed to the dependent population presenting a "window of opportunity" that is conducive for rapid economic development for the country; an opportunity that needs to be utilized immediately as the number of dependents will increase in future due to continued declines in fertility and mortality. What the above scenario means for Botswana is that the many people in the working population can only stimulate growth and make a positive contribution economically if the labour market can expand to provide employment for them.

\subsection{Factors That Have Led to the Age Structural Shift in Botswana}

Given that the age structure of the population is influenced to a greater extent by decline in the level of fertility and mortality, it is important to assess how the two have behaved in Botswana for the past 40 years.

\subsubsection{Fertility Levels}

Evidence from censuses suggests that birth rates in Botswana have fallen by almost two thirds from 1981 to 2011; the main influence regarding the declining fertility can be associated with three factors, these being effective use of contraceptives, access to education by most women as well as employment of women outside the home (Figure 5).

\subsubsection{Mortality Levels}

The measures of mortality in Botswana are usually life expectancy at birth, crude death rate, maternal mortality and infant mortality. However, the last two are usually not used, due to unsuitability of the type of data collected. Using life expectancy at birth and childhood mortality as indicators, mortality in Botswana 


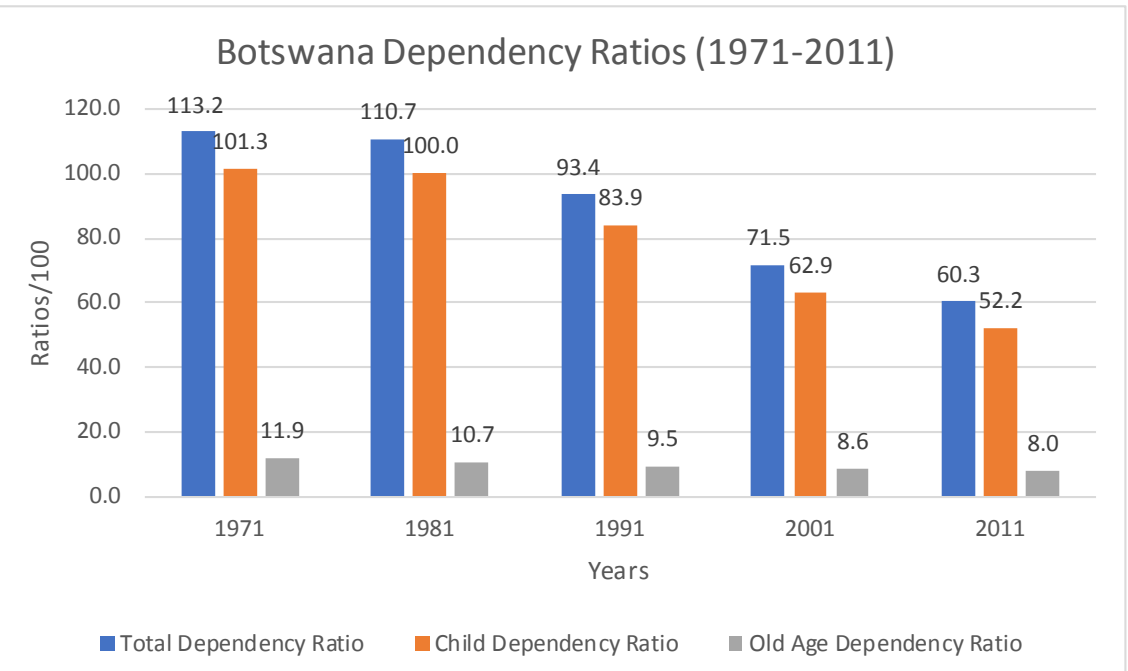

Figure 4. Botswana total dependency ratio's 1971-2011. Source: [13], [14], [15], [16] and [17].

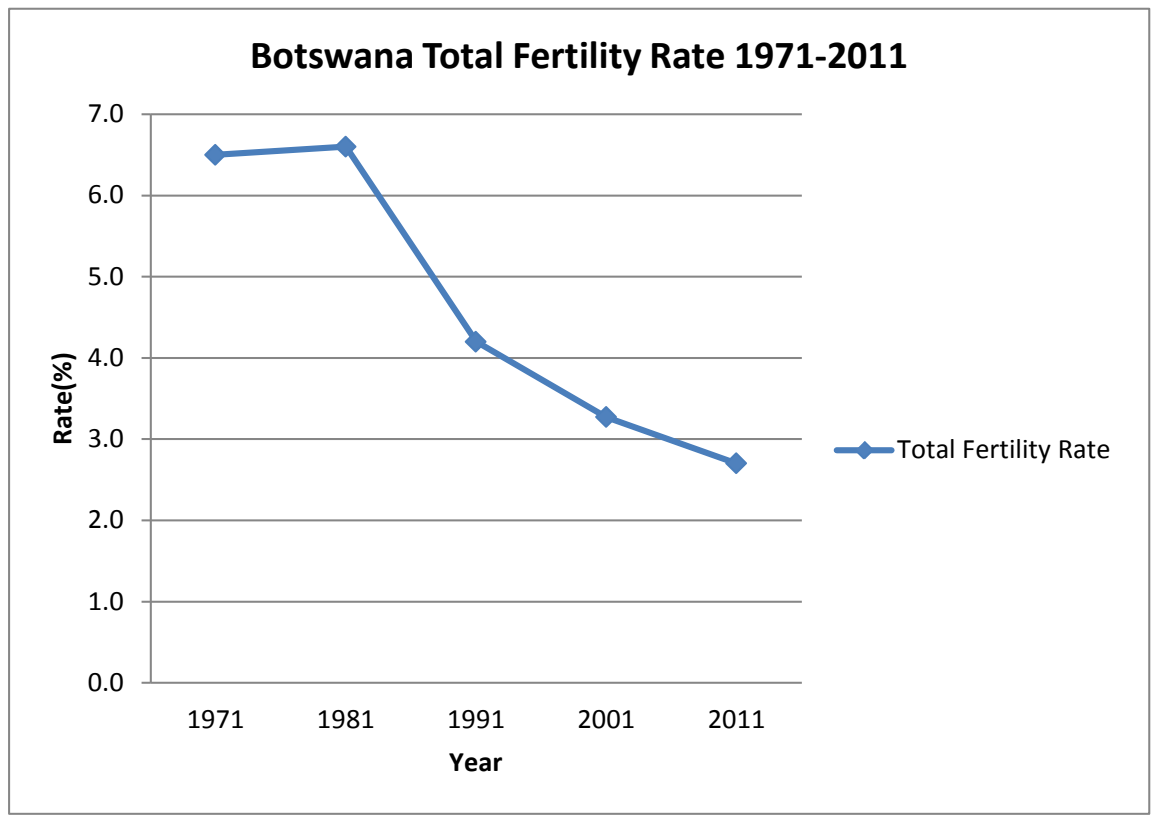

Figure 5. Trends in the level of fertility in Botswana 1971-2011. Source: [17].

as presented in Table 2 was low during the period from 1971 up to 1991. Then, due to an increase in HIV related death rates, the country recorded an increase in the level of mortality in 2001.

\subsubsection{Migration}

International migration in Botswana can be linked to development of mining industry in South Africa. Before the discovery of minerals in the country, and due to poor job opportunities in Botswana, many Batswana migrated to South Africa to work either in the mines, domestic services or even farms. At the time, Botswana was not attracting foreign nationals as there was nothing for them to 
Table 2. Trends in the level of mortality in Botswana 1971-2011.

\begin{tabular}{ccc}
\hline Year & Life Expectancy & Under Five Mortality \\
\hline 1971 & 55.5 & 152 \\
1981 & 56.5 & 105 \\
1991 & 65.3 & 63 \\
2001 & 55.6 & 74 \\
2011 & 68.0 & 28.1 \\
\hline
\end{tabular}

Source: [13], [14], [15], [16] and [17].

do in the country. Only few individuals came to Botswana most of whom were employed in the service sector. However, due to economic improvements in Botswana there has been almost a reverse migration trend where very few Batswana migrate, while a number of non-Batswana are being attracted into the country. Table 3 shows that from 1971 up to 1991, Botswana experienced negative migration rate implying there were more Batswana migrating out than the population entering Botswana. Between 2001 and 2011 Botswana seems to have attracted more foreign national as evidenced by positive migration rates for the two reference periods.

\subsection{Population Growth}

Consistent with the levels of fertility and mortality, population growth in Botswana has slowed down considerably since 1981. The growth rate was highest between 1971 and 1981 at 4.6 percent per year. The latest estimate shows that just like the level of fertility, the population growth rate at 1.9 percent is also turning towards replacement level due mainly to decline in the level of fertility. Both the population and its rates of growth are given in Table 4.

\subsection{The Demographic Dividend in Botswana}

Socio-economic needs of populations change based on age structural changes, thus knowledge of the age structure of a population is vital for planning and providing services for populations. As generations or cohorts of differing ages and sizes pass through key life-cycle stages there are potential opportunities, demographic and policy implications of such a passage as different people need different infrastructure and services in any given society [19]. For instance, a rise in the number of workers than young dependents needs accompanying increased investments in family planning, education, and child survival in order for a country to realise economic growth [20]. Economic investment is also critical for employment generation and subsequent wealth creation and savings for the realisation of the dividend.

Botswana has realised a rise in the number of workers than young dependents from 1991 to date. It also has a youthful structure that is entering the economically 
Table 3. Trends in International migration in Botswana 1971-2011.

\begin{tabular}{cccc}
\hline Year & Immigrants & Emigrants & Net Migration \\
\hline 1971 & 1.9 & 8.0 & -6.1 \\
1981 & 1.6 & 4.3 & -3.2 \\
1991 & 2.2 & 2.9 & -0.6 \\
2001 & 3.6 & 1.7 & 1.4 \\
2011 & 5.5 & 1.1 & 4.1 \\
\hline
\end{tabular}

Source: [13], [14], [15], [16] and [17].

Table 4. Population size and growth.

\begin{tabular}{ccc}
\hline Period & Population Size & \% Growth \\
\hline 1971 & 574,094 & - \\
1981 & 971,027 & 4.6 \\
1991 & $1,326,796$ & 3.5 \\
2001 & $1,680,863$ & 2.4 \\
2011 & $2,024,904$ & 1.9 \\
\hline
\end{tabular}

Source: [13], [14], [15], [16] and [17].

productive ages, and enjoys a stable economy, an improvement in health after the rise in deaths due to HIV/AIDS, a good education system, which could bring about economic growth to the country if employment opportunities were created. [10] state that windows of opportunity provide favourable conditions for society to re-formulate social policies regarding education and health for the children. Since Botswana has entered the window of opportunity, it is important for the country to take the necessary steps to harness the demographic dividend.

[5] also demonstrates that the mere existence of a favourable demographic dividend would be ineffective without a proper environment for economic acceleration. An increasing working age population seeking gainful employment, but with no proper job opportunities will be a dilemma for a country. He however notes that where the environment is conducive, the optimum utilization of the demographic dividend to gain economic acceleration would materialize.

Scholars also argue that the demographic dividend is not permanent but rather a temporary window of opportunity which if not capitalised on, may not be optimised or yet still be forfeited. The reaping of the dividend is not guaranteed but rather calls for effective and pragmatic initiatives for its realisation [21] [22] [23]. Countries which implement efficient policies are most likely to capitalise on the dividend than those with less efficient policies. Korea is one country often cited as an example of a country which had capitalised on the dividend effectively compared to some other countries for which it was comparable to in the 
1960s. A failure to optimise the dividend may create more problems when the economically active population enter the stages of dependency when the bulging of the population would be for the elderly. The lack of or low savings resulting from the failure to capitalise on the dividend through economic growth and employment creation may come to haunt a nation as it faces a burden rather than dividend [21] [22].

The demographic dividend is still a part of the demographic transition. Its demise will be marked by an increase in the dependency ratio as the population of those aged above 64 increases. This occurs because the elderly would now be ceasing to be part of the labour force and may have to depend on the relatively shrinking economically active population. The bulge of the population will now be at older ages meaning that the dependency burden is now more driven by the elderly as against before the dividend when it was largely driven by children at the ages below 15 years.

It is important to have a clear understanding of the opportunities that the demographic dividend avails and how such opportunities could be utilised. Firstly, a decline in fertility reduces the proportion of children as those of working age increase. This has two prolonged economic effects for which the optimisation of the dividend is premised. The number of children reduces and so is the investment into their education which releases resources for investment into some other economic areas including in education at relatively higher levels such as secondary and tertiary and Korea capitalised on this opportunity very effectively [21] [23]. Such a measure enhances the productivity within the economy through the development of the human capital. An enhanced productivity holding all other things constant will act as an impetus to economic growth and possibly development. It is therefore important that the resources realised following the decline of fertility are invested wisely for the harnessing of the dividend.

Secondly, an increase in the population of the economically active is a direct increase in the supply of labour. This results from at least two factors that being the entry into the working population by children born during the high fertility era as well as the release of women into the labour force as they now have to contend with fewer children. This increase in the labour force is an increase in the available resources necessary for economic growth and development. However, this increase requires that government implements wise policies which will enable the creation of more job opportunities for the increasing labour supply, failure of which may culminate in social unrests as millions of citizens remain unemployed [21].

In the face of prudent economic policies, job creation and economic growth will be attained and given the diminished dependency burdens; there will be enhanced capacity for income generation and wealth. This avails another medium of delivery of the economic benefits of the dividend, that being an increase in savings which will come in handy at old age. The savings increase because of reduced dependency burdens, increased employment. The fact that generally 
working age population earn relatively more than the very young and given that the saving ability is enhanced when those of working age are in their 40 's meaning that their children might also be independent and serve as complementary factors in fostering savings [21]. This savings may then translate into partial resource for industrial investments which may drive economic growth as such are reinvested for further economic expansion [21].

In addition to the increased investment into human capital resulting from reduced investment in the children's education, [21] points out to some other factors which equally affect the human capital positively. Such factors include the enhancement of; women's health as a result of few children; their social status and personal independence emanating from participation in the labour force; more energy for an effective contribution to their families and society in general and increased provision of both health and educational services for children, including girls.

The effectiveness of policy choices in harnessing the demographic dividend is cited as a typical explanatory variable in explicating the variations in reaping the economic benefits of the dividend amongst the South-east Asian countries. The variation in the skills and competencies of the productive labour force across these countries is viewed as the key factor in explaining the inconsistency in harnessing the dividend within the area [22]. There is a general consensus that one key ingredient in realising the dividend lies in utilising effectively the economically active population so as to drive economic growth and development with a view to provide resources for the future. The dividend has been harnessed quite well in the four decades before 2004 by the countries of Asia and Latin America with Africa lagging behind due to her failure to reduce fertility rates [24].

\section{The Wheels Driving the Demographic Dividend}

The optimisation of the economic dividend in often cited to be dependent upon four key wheels. Once the population transition has ushered in the dividend, there is a need for a number of measures to be undertaken so as reap the economic benefits. These key measures are demonstrated by the four small wheels as provided in Figure 6. It has been noted that Education, health, economics (in particular policies), and governance are mutually critical in harnessing the demographic dividend [22] and [23].

\subsection{Education}

Education is considered key in enhancing productivity within the economy through better or higher education which translates into better and improved human resource, thereby culminating in enhanced productivity [22]. Whereas the Millennium Development Goal of universal primary education is the focus of most of the countries, the quality of education still remains a major challenge [23]. In respect to education, Botswana has done relatively well; since independence she 


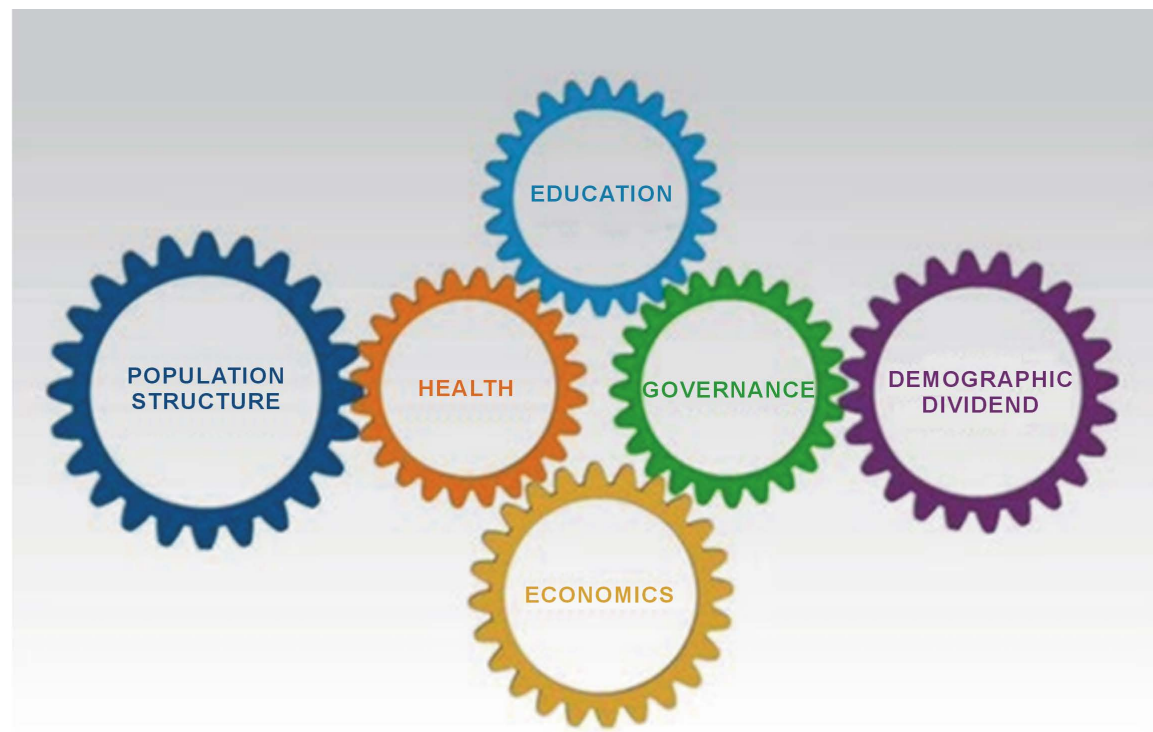

Figure 6. Wheels driving the demographic dividend. Source: [20].

has given priority to improving her education thus improving the quality of education in the process. This was partially aided by the implementation of the Revised National Policy on Education in 1994, which among other factors seeks to increase access and equity in education and training through both formal and non-formal education. Botswana also put in place Vision 2016 pillars; where one of the aims was to turn Botswana into an informed and educated nation [2].

Given the above commitment, the current enrolment rate at primary level is almost 100 percent and remains almost the same up to junior secondary as progression to junior secondary is almost 100 percent and drop out due to pregnancy has declined due to a change of policy in which pregnant students may remain in school until their $3^{\text {rd }}$ trimester and after delivery be admitted back into the school system. The sex ratio at primary and junior secondary levels favours girls, a general reflection of the national sex ratio at that age. Progression to senior secondary and tertiary level is still a challenge with progression to senior secondary estimated at about 50 percent, while it's much less for tertiary level even though it has improved with an increase in the number of tertiary institutions.

Although Botswana enjoys high access to basic education as well as free education up to university level, there are concerns regarding her quality of education, its relevance and suitability to the country's development needs. Some of these concerns arise since generally graduates within the country are failing to find employment [2]. A factor that can be detrimental to harnessing the demographic dividend since an idle labour force is of no benefit to the country's economy.

\subsection{Health}

A healthy population is also central to harnessing the dividend. Improving the 
health of the population helps to mitigate against the losses of household income as poor health is considered to lead to losses in household income [21]. As with education, Botswana has done relatively well in ensuring she has a healthy population, with most people currently living within five kilometres of a health facility. HIV/AIDS which has previously eroded gains in life expectancy and reversed reductions in both child and adult mortality rates remain the main challenge for the country. The most affected population being those in the reproductive ages where the infection rate is above 30 percent.

However, Botswana as one of the countries ravaged by HIV/AIDS was the first country in Africa to offer free HIV prevention, treatment and care services. Furthermore, the country was also one of the first to implement a comprehensive strategy to respond to the HIV/AIDS epidemic [2]. Government also collaborated with development partners to put programmes in place such as the Prevention of Mother to Child Transmission and the Anti Retroviral Therapy Programmes, Routine HIV Testing and Behavioural Change Interventions and Communications. These factors would lead to gains in life expectancies and reductions in under 5 mortalities. Although Botswana has made significant strides in the fight against HIV/ AIDS, the epidemic remains a major challenge for the country as the national HIV prevalence rate stood at 18.5 percent [25].

Other than HIV/AIDS, non-communicable diseases such as: diabetes, stroke, hypertension, and cancer are reported to have increased since 2004; with mortality and deaths from Tuberculosis having risen since the 1990's mainly due to HIV/TB co-infection [2].

\subsection{Governance}

Good governance is paramount in the promotion of foreign and domestic investment as it gives potential investors the confidence that contracts will be honoured, and laws enforced. The infusion of foreign investment also brings with it technical skills and employment creation opportunities which are critical for optimising the dividend [22]. Good governance entails amongst others practical zero tolerance for corruption, transparency, accountability and efficiency in the operations of government. It therefore fosters the confidence necessary for investment within the economy as investors would know that palm greasing would not be the vent for accessing services necessary for the success of their investment ventures.

In the presence of good governance, gender equality is most likely to be promoted. This will enable women to have access to family planning and accord them the opportunity to work outside the home and thereby contribute to the economic wellbeing of their families [22]. They will also have the opportunity to have access to credit and the right inheritance, the result of which will be an increased opportunity to save and invest [22].

Botswana stands out as the least corrupt country in Africa. This is indicative of a very good attribute necessary for harnessing the dividend. There is however 
some perception that corruption is still high in Botswana and possibly increasing. If indeed this is true, particularly given that even this rating is a product of perceptional studies, the high rating may mean that the best is not good enough. In addition, it may also mean that the world is mostly corrupt as we rank as 32 in the whole world. Some of the major projects which had great potential in driving the country's development have not borne fruit albeit clouded in corruption allegations. In this regard the Morupule Power Plant B, The Feyngyne Glass project in Palapye and the near collapse of Botswana Meat Commission stand out as often cited problems of corruption [26]. That heads did not roll, could be well and rightly construed as tolerance for corruption amidst the monotonous rhetoric for zero tolerance for corruption as often alleged by government. The government should put her words to practice by indeed having zero tolerance for corruption, both in the spirit of good governance and by extension in maximizing potential gains of the dividend and overall economic development of the country.

The efficiency of government can also be put to question in view of the poor performance within certain ministries. The educational sector has been underperforming quite consistently in the recent past despite the heavy investment into the sector. The health sector has also been occasionally clouded by inadequate supplies of health medicines when millions of such medicines have been destroyed due to expiry. This does not only point to wastage of resources but also misallocation of scarce resources, thereby potentially undermining the optimisation of the dividend.

While efforts have been made to empower women as attested by the ever-increasing number of women in positions of authority, more still needs to be done. The education of women has proven a worthwhile effort and should be thus increased and intensified as a means towards their empowerment. This has the potential to help optimize on the dividend.

\subsection{Economics}

Economic policies that promote growth are key in optimising the dividend. Such policies should be able to promote savings and investment and ensure that locally produced products would have access to international markets [22]. A flexible productive and skilled labour force complemented by efficient institutions such as banks and other financial entities are key in promoting investment which is critical in driving the economy towards high levels. In addition, tax incentives and infrastructural developments are needed for an efficient operation of the entire economic system for the realisation of maximum dividends [22].

In Botswana's context it must be borne in mind that the economy has found diversification illusive despite the numerous policy initiatives that have been put in place. A series of initiatives such as the Financial Assistance policy (FAP), Botswana Export Development and Investment Agency (BEDIA), Botswana Investment and Trade Centre (BITC) and Citizen Entrepreneurial Development 
Agency (CEDA) amongst others, have been undertaken in pursuit of diversification albeit with minimal success if any. The repercussions of this failure have been high levels of unemployment, inequality and poverty, which have been viewed to be inconsistent with what is observable within comparable middle-income economies. These levels are comparable with those found within low income countries.

The drive to diversification remains the only hope towards addressing these problems. The pursuit of foreign direct investment as one of the means towards the realisation of this goal has not borne any significant fruits, save for the capital-intensive mining sector. There is therefore a need of an economic paradigm shift with a view to utilize local resources particularly in the hands of government to establish enterprises as a way towards increasing the economic base of the country. The country's relatively stable financial standing accords it the opportunity to fill the gaps that the private sector seems reluctant to capitalise on. The costs of a narrow-based economy were well amplified when the Botswana economy shrank quite significantly in comparison with some of the Southern African regional economies.

The arable agricultural sector, in particular the horticultural sector could help in economic diversification. The development of the sector calls for necessary measures to be instigated, which could foster productivity and effectiveness of the sector. To this end every effort should be made including assisting the farmers in the provision of underground water and the importation of labour with minimal impediments. The provision of subsidised electricity connections may also come in handy as the absence of utility has proven a challenge given the intensity of electricity use in irrigation. The development of the sector will substantially reduce the import bill and help promote manufacturing as envisaged under Selebi Phikwe Economic Diversification Unit (SPEDU). The high import bill which is around two billion pula's (Botswana's currency) is testimony to the existence of a market for the sub-sector.

\subsection{The Cost and Benefit Aspect of the Demographic Dividend (DD)}

The demographic transition in Botswana is at a stage where the numbers of those of working age constitute 64.9 percent of the total population. This simply means that those outside the labour force or the dependents account for 35.1 percent of the population as per the 2011 population and housing census. The dependents comprise children and elderly, defined earlier as those aged below 15 years and above 64 years respectively. This stage of the demographic transition has come to be known as the demographic dividend. It is considered a period within the demographic transition which accords greater potential for economic growth and human development through increased savings, investment, consumption and productivity amongst others [21] [22]. It is estimated that a third of the growth experienced by the East Asian Tigers was attributable to the de- 
mographic dividend [21].

\section{Conclusions and Implications}

Botswana has experienced an age structural transition since 1971 to date as there has been a change in the age structure of the population for the age groups $0-14$ years and the productive age group of 15 - 64 while the proportion of those aged 65 years and above has remained almost the same throughout the years. Both fertility and mortality have declined considerably over the years though a peak in mortality was experienced with the advent of HIV/AIDS in the country. As a result of the general decline in both mortality and fertility the country experienced a shrinking young age group and a bulging working age group over time; a factor that has brought about lower dependency ratios since there are more people of working age in the population relative to dependents. The lower dependency ratios help in the accumulation of wealth and savings, and such accumulations are key for the sustenance of the elderly when the current bulge translates into a greater old age population. However, for this to be realised employment generation is paramount and failure to create a conducive employment climate will render the demographic dividend untenable or marginally realisable.

While there is no direct indicator that the population of Botswana is ageing as given by the constant proportion of those aged above 64 years, an increase in the median age points to the fact that the population of Botswana is ageing. An ageing population is associated with shortage of economically active people and loss of income as most of the people may not be working. It can also lead to the high cost of service provision as well as the high cost of old age pension when those in the working age group reach old age. While there may not be a direct solution to the problem there could be other suggestions such as the government can put in place pronatalist policies that encourage women to have more children than the average of 2.7 children per woman as is the case presently and also to guard against fertility levels dropping beyond replacement level. While an increase in the retirement age can be suggested, a relatively low life expectancy may make the recommendation invalid.

Failure to capitalise on the dividend may prove quite detrimental when the population of the elderly bulges. The government should take a lead in an endeavour to realise the dividend. Effective policy prescriptions are necessary if Botswana is to capitalise on the window of opportunity and maximise on its benefits.

Botswana as earlier indicated is in the midst of the demographic dividend, and it is critical to promote the maximisation of the economic benefits brought about by the population transition. Botswana has fared very well against most of the African countries in so far as areas of economic growth, governance, health and education are concerned with the latter getting a serious dent of late. The quality of education, the performance of students and the relevance of graduates to the 
labour market demands of the Botswana economy have put education on the spot. The problem of graduate unemployment has escalated. Unemployment is officially at around 17.8 percent in its strict definition while it is thought to be relatively high when loosely defined. There is therefore need to ensure that issues of quality of education are addressed in the country in order to benefit from the current tertiary education graduate's youth bulge.

In Botswana's case in which the unemployment rate is quite high, the maximisation of the dividend may prove substantively evasive. It is an opportunity that comes once and if lost the country may in future be overburdened. An idling labour force is a cost to the economy and could be paradoxical in light of the definition of economics. We often define economics as the study of limited resources in the midst of unlimited wants. The human resource which is not utilised is an indictment on this definition. It appears after all that resources may not be as limited as the definition would have us believe.

Botswana's economic prospects remain an issue of intensive speculation as the mining sector, which has remained the main driver of Botswana's so well acclaimed economic success remain highly volatile. The failure of the country to effectively translate the mineral revenues into the development of other industrial sectors of the economy with a view to realise diversification appears to be the major undoing of the Botswana economy. The persistent problems of poverty, unemployment, inequality and most probably mismatch of skills and graduate unemployment stand to frustrate the optimisation of the demographic dividend.

There is need for injection of investment into areas with great potential for employment creation. Both private and public investments intended for employment creation are paramount for the dividend to come to fruition. This will go a long way in addressing the problems aforementioned and pave way for the sustenance of a decent livelihood and wellbeing when the population transits into old age.

The capitalization of the dividend requires that appropriate measures and policies be undertaken. These policies seek to galvanize the five wheels of education, age structure, health, governance and the economy upon which the harnessing of the dependent relies upon. At the governmental level and by extension the country, this window of opportunity is not well known and therefore adequately appreciated. There is a need to sensitize the government and to do research which will highlight priority areas for Botswana to benefit from the DD. Future research is needed so identify gaps and possible remedial measures aimed at optimizing the harnessing of the DD.

\section{References}

[1] Malema, B.W. (2015) Key-Note Address-Creating a Harmonious Environment for Investment and Industrial Relations-Introducing the New Complementary Laws Time Frames-Employment Act, Trade Disputes Act, Workers' Compensation Act and Trade Unions and Employers' Organisations Act. A Key Note Address Deliv- 
ered at the "Botswana Labour Relations and Local Empowerment Market Briefing 2015, 15 \& 16 September 2015. The Grand Palm Hotel Resort, Gaborone.

[2] MFDP and UNFPA (2013) Review and Assessment of the Implementation of the International Conference on Population and Development Programme of Action. Botswana ICPD Country Report 2013.

[3] MFDP (2007) Keynote Policy Paper for National Development Plan 10.

[4] Pool, I. and Wong, L.R. (2006) Age-Structural Transitions Challenges for Development. Committee for International Cooperation in National Research in Demography, Paris, 3-19.

[5] De Silva, W. (2012) The Age Structure Transition and the Demographic Dividend: An Opportunity for Rapid Economic Take-Off in Sri Lanka. Sri Lanka Journal of Advanced Social Studies, 2, 3-46.

[6] Seniloli, K. (2006) To Take Advantage of the Demographic Window of Opportunity or Not. That Is the Question: The Case of Fiji. In: Pool, I., Wong, L.R. and Vilquin, E., Eds., Age-Structural Transitions. Challenges for Development, Cicred, Paris, 201-224.

[7] Navaneetham, K. (2002) Age Structural Transition and Economic Growth: Evidence from South and South-East Asia. Working Paper No. 337, Centre for Development Studies, Thiruvananthapuram.

[8] Hao, Y. (2004) Age Structural Transitions and Major Policy Implications in China. CICRED Seminar on Age-Structural Transitions. Demographic Bonuses, but Emerging Challenges for Population and Sustainable Development, Paris, 23-26 February 2004, 1-25. http://www.cicred.org/Eng/Seminars/Details/Seminars/Popwaves/PopwavesHao.pdf

[9] Nair, P.S. (2004) Age Structural Transition in Botswana in the Context of HIV/AIDS. CICRED Seminar on Age-Structural Transitions Demographic Bonuses, But Emerging Challenges for Population and Sustainable Development, Paris, 23-26 February 2004.

[10] Wong, L.R. and de Carvalho, J.A.M. (1998) Age-Structural Transitions Demographic Bonuses, But Emerging Challenges for Population and Sustainable Development.

[11] UNFPA (n.d.) How Demographers Think about Population's Age and Sex. http://papp.iussp.org/sessions/papp101_s03/PAPP101_s03_070_010.html

[12] Statistics Botswana (2016) Selected Statistical Indicators 1966-2016; Enabling Stakeholders Formulate Policies, Plan and Make Decisions.

[13] Central Statistics Office (1975) 1971 Census of Population and Housing, Administrative and Analytical Report.

[14] Central Statistics office (1985) 1981 Census of Population and Housing, Analytical Report, Botswana Government.

[15] Central Statistics Office (1997) 1991 Census of Population and Housing Analytical Report, Botswana Government.

[16] Central Statistics Office (2003) 2001 Census of Population and Housing Analytical Report.

[17] Central Statistics Office (2013) 2011 Census of Population and Housing Analytical Report.

[18] Madsen, E.L., Daumerie, B. and Hardee, K. (2011) The Effects of Age Structure on Development Policy and Issue Brief PRB. Population Reference Bureau Population 
Handbook, 6th Edition.

[19] Pool, I. (2006) Mapping Age-Structural Transitions: A Comparative Perspective. In: Pool, I., Wong, L. and Vilquin, E., Eds., Age-Structural Transitions: Challenges for Development, CICRED, Paris, Chapter 2, 21-58.

[20] Population Reference Bureau (PRB) (2014) A Practical Guide to Population and Development.

http://www.prb.org/pdf14/guide-population-development.pdf

[21] Ross, J. (2004) Understanding the Demographic Dividend. Policy Project, Washington DC.

[22] Wongboonsin, K., Guest, P. and Prachuabmoh, V. (2005) Demographic Change and the Demographic Dividend in Thailand. Asian Population Studies, 12, 245-256.

[23] Gribble, J.N. and Bremner, J. (2012) Achieving a Demographic Dividend, Population Bulletin. Vol. 67, No. 2. https://www.popline.org/node/566139

[24] Mason, A. and Lee, S.-H. (2004) The Demographic Dividend and Poverty Reduction. A Paper Presented at a Seminar on the Relevance of Population Aspects for the Achievement of the Millennium Development Goals. Population Division, Department of Economic and Population Affairs, United Nations Secretariat, New York.

[25] Statistics Botswana (2013) Botswana AIDS Impact Survey IV (BAIS IV), 2013 Summary Results.

[26] Malema, B.W. (2014) Public Enterprises' Performance Is a Significant Function of Government's Behaviour. Stanbic Bank Quarterly Economic Review, First Issue. 